\title{
IN MEMORY OF ALEXEY BORISOVICH SHABAT
}

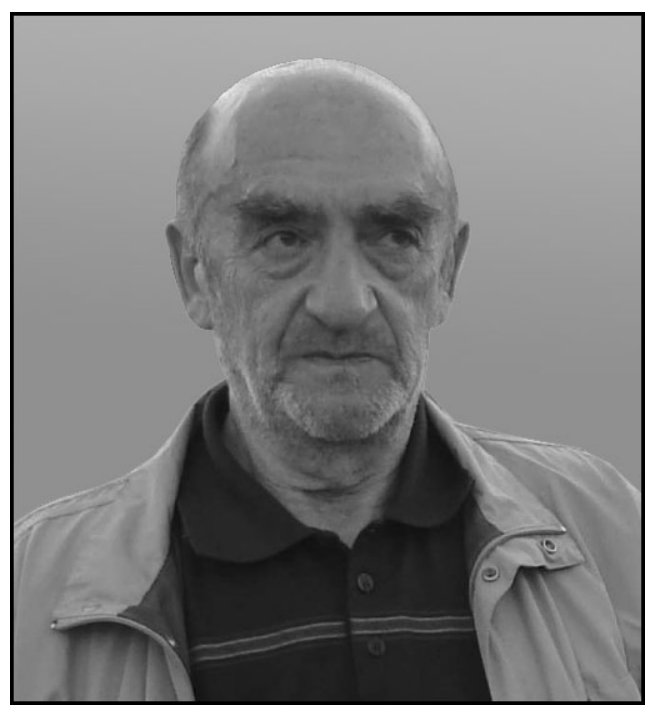

8 August 1937-24 March 2020

DOI: $10.1134 /$ S0040577919050013

The Editorial Board of Theoretical and Mathematical Physics with deep sorrow announces that Alexey Borisovich Shabat, a leading Russian mathematician and one of the founders of the modern theory of solitons, passed away on 24 March 2020. A remarkable person, scientist, and teacher is gone.

After graduating from the Faculty of Mechanics and Mathematics at Moscow State University, Shabat began his scientific activity at the Institute for Hydrodynamics in Novosibirsk, where he defended his candidate's dissertation under the supervision of M. A. Lavrentiev in 1963. From the late 1960s, he participated actively in developing the method of the inverse scattering problem, in which a whole series of his results are fundamental. Shabat was at the source of this important branch of modern mathematical physics, and his contribution underlies its development. He published more than 120 scientific works, of which very many definitively influenced the formation of research directions in this field. Shabat's students include more than ten candidates and six doctors of science.

In different years of his life, Shabat worked at the Ufa Institute of Mathematics and Bashkir State University (Ufa), the Landau Institute for Theoretical Physics (Chernogolovka), Aliyev Karachay-Cherkess State University (Karachaevsk), and Adyghe State University (Maykop). Although the length of these life stages varied, Shabat was true to himself in each of them, actively teaching and generously sharing his ideas. His influence on scientific life is inestimable. Shabat was whole-heartedly devoted to science and continued to work until his last days.

Shabat is buried in Maykop. His relatives, friends, students, and colleagues will always preserve a bright memory of him.

Translated from Teoreticheskaya i Matematicheskaya Fizika, Vol. 203, No. 2, p. 177, May, 2020. Received April 6, 2020. Revised April 6, 2020. Accepted April 6, 2020. 